\title{
A Phase II Study of Adjuvant Chemotherapy of Tegafur-Uracil for Patients with Breast Cancer with HER2-negative Pathologic Residual Invasive Disease After Neoadjuvant Chemotherapy
}

\author{
SATORU TANAKA ${ }^{1}$, MITSUHIKO IWAMOTO ${ }^{2}$, KOSEI KIMURA ${ }^{2}$, YUKO TAKAHASHI $^{3}$, HIYOYA FUJIOKA ${ }^{2}$, \\ NAYUKO SATO $^{4}$, RISA TERASAWA ${ }^{2}$, KANAKO KAWAGUCHI ${ }^{2}$, AYANA IKARI $^{2}$, TOMO TOMINAGA $^{2}$, \\ SAKI MAEZAWA ${ }^{2}$, NODOKA UMEZAKI ${ }^{2}$, JUNNA MATSUDA ${ }^{2}$ and KAZUHISA UCHIYAMA ${ }^{2}$ \\ ${ }^{1}$ Breast Surgery, National Hospital Organization Osaka-Minami Medical Center, Kawachinagano, Japan; \\ ${ }^{2}$ Breast and Endocrine Surgery, Osaka Medical College Hospital, Takatsuki, Japan; \\ ${ }^{3}$ Breast and Endocrine Surgery, Hirakata City Hospital, Hirakata, Japan; \\ ${ }^{4}$ Breast Surgery, Saiseikai Suita Hospital, Suita, Japan
}

\begin{abstract}
Background: There is no consensus on the need for adjuvant chemotherapy for patients with pathological residual invasive breast cancer (non-pCR) after neoadjuvant chemotherapy (NAC). We evaluated the tolerability and safety of tegafur-uracil (UFT) as adjuvant chemotherapy for patients with human epidermal growth factor receptor 2negative breast cancer that resulted in non-pCR after NAC. Patients and Methods: We treated patients with $270 \mathrm{mg} / \mathrm{m}^{2}$ UFT per day for 2 years after definitive surgery and radiotherapy, if necessary. In cases with hormone-sensitive cancer, patients received concurrent endocrine therapy. The primary end-point was the rate of completion of scheduled UFT therapy. Secondary end-points included safety and disease-free survival. Results: Twenty-one out of 29 patients $(72 \%)$ completed the scheduled therapy. Eight patients discontinued the study treatment because of disease recurrence, toxicities, and patients' wish. Excluding liver dysfunction, adverse events were quite mild. Conclusion: Adjuvant UFT therapy after NAC was feasible and safe.
\end{abstract}

Neoadjuvant chemotherapy (NAC) is widely used for both locally advanced and early-stage breast cancer. The advantages of NAC include determining tumor responses to specific treatment regimens in clinical practice and providing

This article is freely accessible online.

Correspondence to: Satoru Tanaka, Breast Surgery, National Hospital Organization Osaka-Minami Medical Center, 2-1 Kidohigashicho, Kawachinagano, Osaka 586-8521, Japan. Tel: +81 721535761, Fax: +81 721538904, e-mail: sur112@osaka-med.ac.jp

Key Words: Tegafur-uracil, breast cancer, neoadjuvant chemotherapy, pathologic complete response. an opportunity for down-staging to avoid mastectomy for inoperable tumors or breast-conserving surgery in cases originally requiring mastectomy $(1,2)$. Anthracyclines and taxanes have been used as the standard chemotherapeutic regimens for breast cancer, however, tumoral estrogen receptor (ER) and human epidermal growth factor receptor 2 (HER2) statuses are important predictors of response to chemotherapy (3-5). Sensitivity to NAC is lower in ERpositive and HER2-negative cancer than in other subtypes. An earlier study of NAC with anthracyclines and taxanes reported an approximately $25 \%$ pathological complete response $(\mathrm{pCR})$ rate in cases of operable breast cancer without taking in mind the ER and HER2 status (6). Furthermore, patients achieving pCR have a more favorable prognosis than patients with pathological residual invasive disease (non-pCR) (6-8). Adjuvant endocrine therapy for ERpositive breast cancer and anti-HER2 therapy (e.g. Trastuzumab) for HER2-positive breast cancer after NAC currently represent the gold-standard of care. There is a lack of consensus regarding the requirement for an adjuvant chemotherapy in cases with non-pCR after NAC; however, further chemotherapy may improve patient outcomes. Adjuvant chemotherapy is typically appropriate in patients with non-pCR because patients with operable breast cancer frequently experience tumor recurrence approximately 2 years after initial surgery (9).

Long-term, daily oral treatment with tegafur-uracil (UFT) is widely used as an adjuvant chemotherapy for breast, gastric, and colorectal cancer in Japan. (10). A pooled analysis of six randomized, controlled trials demonstrated the survival benefits of adjuvant UFT plus tamoxifen compared to tamoxifen alone for ER-positive early breast cancer (11). Moreover, two randomized, controlled trials demonstrated that UFT therapy for 2 years had similar efficacy to six cycles of cyclophosphamide, methotrexate, and 5-fluorouracil (CMF) 
$(12,13)$. A combined analysis of these trials demonstrated that UFT was non-inferior to CMF in terms of inhibiting the recurrence of ER-positive, early breast cancer (14). UFT therapy is associated with a lower rate of adverse events (e.g. gastrointestinal symptoms, bone marrow suppression, and hair loss) and better quality of life compared with CMF therapy $(10,12)$. However, the safety of UFT therapy in patients previously treated with NAC remains unknown.

Therefore, we evaluated the tolerability and safety of adjuvant UFT chemotherapy for 2 years in patients with HER2-negative breast cancer with non-pCR after standard anthracycline- and taxane-based NAC to assess the preliminary efficacy of UFT therapy.

\section{Patients and Methods}

This present study was conducted in accordance with the Declaration of Helsinki and was approved by the Ethics Committee of Osaka Medical College (approval number: 10-798). All the patients provided written informed consent. This study was registered with the University Hospital Medical Information Network-Clinical Trials Registry (UMIN000003835).

Patients. This study was a single-center, prospective, open-label, single-arm, phase II clinical trial. Eligible patients were females aged $\geq 20$ years with HER2-negative operable breast cancer or locally advanced breast cancer that was suitable for definitive surgery after NAC with anthracycline and taxane. Moreover, all the patients were required to have non-pCR that was defined as no histological evidence of residual invasive tumor cells in the breast or axillary lymph nodes (ypT0/Tis and ypN0), according to histological assessments of surgical specimens. Immunohistochemical analyses for ER, progesterone receptor $(\mathrm{PgR})$, and HER2 were performed for all tumors. Tumors with $\geq 1 \%$ positively stained tumor cells were classified as positive for ER and PgR. HER2 negativity was defined as 0 or $1+$ staining intensity using immunohistochemistry (IHC) or in case with $2+$ by IHC with negative for HER2 gene amplification by fluorescence in situ hybridization (FISH). A FISH ratio of $<1.8$ was considered negative. Patients were required to have an Eastern Cooperative Oncology Group performance status of $<2$, adequate organ function [aspartate transaminase (AST), alanine transaminase (ALT), and bilirubin levels at $\leq 1.5$-times the upper limit of normal; leukocyte count of $\geq 3,000 / \mathrm{ml}$; neutrophil count of $\geq 2,000 / \mathrm{ml}$; thrombocyte count of $\geq 10 \times 10^{4} / \mathrm{ml}$; serum creatinine level of $\leq 1.5 \mathrm{mg} / \mathrm{dl}$; and normal cardiac function on electrocardiography], and no carry-over grade 2 or higher adverse events (except for alopecia) from NAC. Patients with a confirmed infection, serious concomitant illness (e.g. severe cardiovascular disease, uncontrolled diabetes, malignant hypertension, or hemorrhagic disease), active concomitant malignancy, brain metastasis, history of severe drug allergy, or previous treatment with oral CMF-based chemotherapy were excluded from this study. Pregnant and lactating women were also excluded. Mammography, ultrasonography, magnetic resonance imaging, or computed tomography was used to determine the presence of tumors.

Treatment. Each patient received $270 \mathrm{mg} / \mathrm{m}^{2}$ UFT per day for 2 years (Table I). Toxicities were evaluated on a monthly basis using the National Cancer Institute Common Terminology Criteria for
Table I. Dose and administration of tegafur-uracil.

\begin{tabular}{lcc}
\hline Body surface area $\left(\mathrm{m}^{2}\right)$ & Daily dose $(\mathrm{mg})$ & Morning-evening $(\mathrm{mg})$ \\
\hline$<1.3$ & 300 & $200-100$ \\
$1.3-1.67$ & 400 & $200-200$ \\
$\geq 1.67$ & 500 & $300-200$ \\
\hline
\end{tabular}

Table II. Dose reduction of tegafur-uracil per day.

\begin{tabular}{lccc}
\hline $\begin{array}{l}\text { Body surface } \\
\text { area }\left(\mathrm{m}^{2}\right)\end{array}$ & $\begin{array}{c}\text { Starting dose } \\
(\mathrm{mg})\end{array}$ & $\begin{array}{c}\text { 1st step } \\
(\mathrm{mg})\end{array}$ & $\begin{array}{c}\text { 2nd step } \\
(\mathrm{mg})\end{array}$ \\
\hline$<1.3$ & 300 & Discontinued & - \\
$1.3-1.67$ & 400 & 300 & Discontinued \\
$\geq 1.67$ & 500 & 400 & 300 \\
\hline
\end{tabular}

Adverse Events (version 4.0) (15) and blood examinations throughout the treatment. Treatment was withheld for hematological toxicities, including leukocyte count of $<3,000 / \mathrm{ml}$, thrombocyte count of $<7.5 \times 10^{4} / \mathrm{ml}$, hemoglobin level of $<9.0 \mathrm{~g} / \mathrm{dl}$, AST/ALT level of $\geq 100 \mathrm{IU} / 1$, bilirubin level of $\geq 2.0 \mathrm{mg} / \mathrm{dl}$, or grade 2 or higher non-hematological toxicities (anorexia, nausea, vomiting, diarrhea, and stomatitis), until improvement of these toxicities was confirmed. Once adverse events (AEs) had improved following treatment interruption, the UFT dose was reduced from the initial dose at the discretion of the treating physician. The UFT dose reductions are shown in Table II. Study treatment was discontinued in cases of disease progression or unacceptable toxicity. Supportive care was provided according to standard practices. All the patients with ER-positive tumors concurrently underwent UFT therapy with adjuvant tamoxifen or aromatase inhibitor endocrine therapy (postmenopausal women only). Additional treatment with a luteinizing hormone-releasing hormone analog could be provided to premenopausal patients. UFT administration was initiated after radiotherapy in patients requiring postoperative radiotherapy.

Study endpoints. The primary study endpoint was the rate of completion of scheduled adjuvant UFT therapy after 2 years. Secondary endpoints included safety and disease-free survival (DFS) rate. DFS was defined as the time from the initiation of UFT therapy to either the first recurrence or relapse, second cancer, or death.

Statistical analyses. As this trial was an exploratory study to evaluate the utility of continuous adjuvant UFT therapy in patients previously treated with NAC and there are currently no data from previous studies evaluating the tolerability of adjuvant UFT as a primary endpoint, we did not calculate a formal sample size using statistical data from previous comparable studies. Moreover, we considered that a number of cases were required for further exploratory analyses. Consequently, accrual of 50 patients was planned for this study. DFS was calculated using the Kaplan-Meier method. Statistical analyses were performed using SAS version 11.0 (SAS Institute, Cary, NC, USA). 
Table III. Patient characteristics.

\begin{tabular}{|c|c|}
\hline Characteristic & No. of patients $(n=30)$ \\
\hline Median age, years (range) & $51(29-67)$ \\
\hline \multicolumn{2}{|l|}{ Performance status } \\
\hline 0 & $30(100 \%)$ \\
\hline 1 & $0(0 \%)$ \\
\hline \multicolumn{2}{|l|}{ Menopausal status } \\
\hline Premenopausal & $14(47 \%)$ \\
\hline Postmenopausal & $16(53 \%)$ \\
\hline \multicolumn{2}{|l|}{ Clinical tumor stage } \\
\hline $\mathrm{T} 1$ & $4(13 \%)$ \\
\hline $\mathrm{T} 2$ & $13(43 \%)$ \\
\hline $\mathrm{T} 3$ & $7(23 \%)$ \\
\hline $\mathrm{T} 4$ & $6(20 \%)$ \\
\hline \multicolumn{2}{|l|}{ Clinical nodal stage } \\
\hline No & $5(17 \%)$ \\
\hline N1 & $24(80 \%)$ \\
\hline N2 & $1(3 \%)$ \\
\hline \multicolumn{2}{|l|}{ Clinical stage } \\
\hline I & $3(10 \%)$ \\
\hline II & $14(47 \%)$ \\
\hline IIIA & $7(23 \%)$ \\
\hline IIIB & $6(20 \%)$ \\
\hline \multicolumn{2}{|l|}{ ER status } \\
\hline Positive & $21(70 \%)$ \\
\hline Negative & $9(30 \%)$ \\
\hline \multicolumn{2}{|l|}{ PgR status } \\
\hline Positive & $17(57 \%)$ \\
\hline Negative & $13(43 \%)$ \\
\hline \multicolumn{2}{|l|}{ Triple-negative breast cancer } \\
\hline Yes & $8(27 \%)$ \\
\hline No & $22(73 \%)$ \\
\hline \multicolumn{2}{|l|}{ Neoadjuvant chemotherapy } \\
\hline FEC $\rightarrow$ docetaxel & $28(93 \%)$ \\
\hline Docetaxel $\rightarrow$ FEC & $2(7 \%)$ \\
\hline
\end{tabular}

ER: Estrogen receptor; PgR: progesterone receptor; FEC: 5-fluorouracil, epirubicin, cyclophosphamide.

\section{Results}

Patient population. Because of a slow accrual rate to this study, we terminated the entry of patients before reaching the target number. A total of 30 patients were enrolled from September 2010 to March 2014. One patient withdrew consent before receiving the study treatment. Thus, the data of 29 patients were included in the end-point analyses of this study. Patient characteristics are shown in Table III. The median age of the patients was 51 years (range $=29-67$ years). Fourteen patients $(47 \%)$ and 13 patients $(43 \%)$ had stage II and III breast cancer, respectively. Of 30 patients, 21 (70\%) had ER-positive breast cancer and 17 (57\%) had PgRpositive breast cancer. Eight (27\%) patients had ER-negative, PgR-negative, and HER2-negative breast cancer (triplenegative breast cancer, TNBC). We administered the
Table IV. Most common treatment-related adverse events $(n=29)$.

\begin{tabular}{|c|c|c|c|c|}
\hline Adverse event & Grade 1 & Grade 2 & Grade 3 & Grade 4 \\
\hline \multicolumn{5}{|l|}{ Hematological, n (\%) } \\
\hline Leucopenia & $3(10 \%)$ & $7(24 \%)$ & $1(3 \%)$ & 0 \\
\hline Neutropenia & $1(3 \%)$ & $4(14 \%)$ & $1(3 \%)$ & 0 \\
\hline Anemia & $3(10 \%)$ & 0 & 0 & 0 \\
\hline Thrombocytopenia & $4(14 \%)$ & 0 & 0 & 0 \\
\hline Hyperbilirubinemia & $6(21 \%)$ & $3(10 \%)$ & 0 & 0 \\
\hline Alanineaminotransferase & $7(24 \%)$ & $1(3 \%)$ & $2(7 \%)$ & 0 \\
\hline Aspartateaminotransferase & $10(34 \%)$ & $1(3 \%)$ & $1(3 \%)$ & 0 \\
\hline Hyperuricemia & $1(3 \%)$ & 0 & 0 & 0 \\
\hline \multicolumn{5}{|l|}{ Non-hematological, n (\%) } \\
\hline Fatigue & $8(28 \%)$ & 0 & 0 & - \\
\hline Anorexia & $5(17 \%)$ & $1(3 \%)$ & 0 & 0 \\
\hline Nausea & $4(14 \%)$ & 0 & 0 & - \\
\hline Vomiting & 0 & 0 & 0 & 0 \\
\hline Stomatitis & $1(3 \%)$ & $1(3 \%)$ & 0 & 0 \\
\hline Dysgeusia & $3(10 \%)$ & $2(7 \%)$ & 0 & 0 \\
\hline Diarrhea & $4(14 \%)$ & 0 & 0 & 0 \\
\hline Rash & $2(7 \%)$ & $1(3 \%)$ & 0 & 0 \\
\hline Skin hyperpigmentation & $12(41 \%)$ & $1(3 \%)$ & - & - \\
\hline
\end{tabular}

combination of $\mathrm{CMF}$, epirubicin, and cyclophosphamide every 3 weeks $(q 3 w)$ for four cycles and docetaxel $q 3 w$ for four cycles to all patients as NAC.

Treatment administration and study completion. Initial doses of UFT were $400 \mathrm{mg}$ and $500 \mathrm{mg}$ in 24 and 5 patients, respectively. Eleven patients $(38 \%)$ required dose reduction or interruption. Of these, eight patients (28\%) required firststep dose reductions of UFT because of neutropenia $(n=2)$, hyperbilirubinemia $(n=3)$, elevated AST/ALT levels $(n=1)$, and diarrhea $(n=1)$. Interruptions of UFT therapy occurred in $31 \%$ of patients ( 9 out of 29 patients) because of leucopenia $(n=2)$, neutropenia $(n=1)$, elevated AST/ALT levels $(n=2)$, hyperbilirubinemia $(n=1)$, fatigue $(n=1)$, stomatitis $(n=1)$, and rash $(n=1)$. A total of 21 patients $(72 \%)$ completed the scheduled adjuvant UFT therapy with or without dose reductions. The rate of compliance without dose reduction was $55 \%$ (16 out of 29 patients). Eight patients discontinued the study treatment because of disease recurrence $(n=1)$, delayed improvement of elevated AST/ALT levels $(n=2)$, dysgeusia $(n=1)$, rash $(n=1)$, deep vein thrombosis due to tamoxifen $(n=1)$, and patient wish $(n=2)$. The mean total UFT dose was $79.4 \%$ of the target dose. After a median follow-up of 4.2 years (range=2.5-6.1 years), the DFS rate was $82 \%$.

Safety profile. The incidences of treatment-related AEs are shown Table IV. Overall, AEs related to UFT therapy were mild in this study. Elevated AST and ALT levels were the 
most frequent grade $3 \mathrm{AEs}$ that were observed in $7 \%$ and $3 \%$ of patients, respectively. Grade 3 leucopenia and neutropenia were both observed in $3 \%$ of patients. We observed important common non-hematological toxicities of various grades, including anorexia, stomatitis, dysgeusia, rash, and skin hyperpigmentation. No grade 3 or greater non-hematological AEs or unexpected serious AEs were observed in this study.

\section{Discussion}

In this study, we evaluated the tolerability and safety of UFT as an adjuvant chemotherapy in patients with HER2-negative breast cancer with non-pCR after standard anthracycline- and taxane-based NAC. The rate of completion of scheduled adjuvant UFT therapy after 2 years (the primary study endpoint) was $72 \%$ (21 out of 29 patients). Furthermore, the rate of compliance without dose reduction was 55\% (16 out of 29 patients). These findings are comparable with previous studies using the same regimen. The National Surgical Adjuvant Study for Breast Cancer 01 Trial compared the efficacy of six cycles of classical cyclophosphamide, methotrexate, and CMF with 2 years of UFT in patients with node-negative, high-risk breast cancer and reported a $64 \%$ compliance rate with or without dose reduction at 2 years in the UFT arm (12). In addition, the mean total UFT dose of $79.4 \%$ of the target dose in this study was comparable with a previous randomized study that compared UFT therapy for 2 years with classical CMF in patients with node-positive breast cancer (75\%) (13).

Currently, adjuvant endocrine therapy for ER-positive and anti-HER2 therapy for HER2-positive breast cancer remain the standard-of-care, irrespective of the response (pCR or non-pCR) to NAC. In contrast, additional adjuvant chemotherapy in cases with pCR may represent over-treatment; however, further chemotherapeutic treatment may improve patient outcome in non-pCR cases. Recently, differences in response to NAC have been demonstrated to affect patient outcomes among certain subtypes of breast cancer. In high-risk ER-positive and HER2negative (e.g. high-grade, high Ki-67 index) breast cancer and TNBC, pCR cases may have a more favorable prognosis than non-pCR cases $(16,17)$. As tumor recurrence often occurs approximately 2 years after initial surgery in these subtypes of breast cancer, adjuvant UFT therapy may be reasonable in nonpCR cases. Experimental evidence suggests that the prevention of recurrence by UFT involves the inhibition of angiogenesis in addition to the cytotoxic activity of fluorouracil (18). Long-term treatment with UFT may prolong the dormant status of micrometastases, thereby preventing recurrence.

AEs related to UFT therapy were quite mild in this study. Although we observed grade 3 hematological toxicities, there were no cases of grade 4 hematological toxicities or grade 3 or higher non-hematological toxicities. Elevated AST and ALT levels were the most frequent grade 3 AEs, observed in $7 \%$ and $3 \%$ of patients, respectively. Grade 3 leucopenia and neutropenia were both observed in 3\% of patients. These findings corroborate the findings of previous randomized studies $(12,13)$. Despite the concurrent use of UFT and endocrine therapy in patients with ER-positive breast cancer in this study, no increase in the incidence of AEs related to UFT were observed with the combination of these agents. Although oral fluoropyrimidines, such as UFT, are generally considered to be associated with a relatively low frequency of AEs, the incidence of liver dysfunction requires attention. Therefore, patients who receive UFT or other oral fluoropyrimidine therapy should be closely monitored for liver toxicity and undergo regular liver function tests.

The major limitation of this study was the relatively small sample size from a single institution. In addition, we were unable to set a predefined sample size according to statistical data from previous studies. We were also unable to meet the planned sample size. A further limitation was the lack of quality-of-life assessments, which have utility in estimating the feasibility of the study treatment. However, to the best of our knowledge, this is the first report evaluating the tolerability and safety of UFT in the adjuvant setting for patients who were previously treated with anthracycline- and taxane-based NAC.

In conclusion, adjuvant UFT therapy for 2 years in patients previously treated with anthracycline- and taxane-based NAC is well tolerable with a low incidence of adverse events related to toxicity. Large randomized trials are warranted to evaluate the efficacy of UFT as an adjuvant chemotherapy. Regarding the efficacy of oral fluoropyrimidines as an adjuvant chemotherapy, Toi et al. reported the results of phase III clinical trial that showed that capecitabine improves survival outcomes for non-pCR cases after NAC (19). Although potentially promising, it is important to consider the benefits and toxicity of additional adjuvant chemotherapy in patient populations similar to that of this study. Accordingly, methods for predicting the therapeutic benefit of such treatment regiments should also be investigated.

\section{Conflicts of Interest}

The Authors have stated that they have no conflicts of interest in regard to this study.

\section{Acknowledgements}

The Authors gratefully acknowledge the participating patients, their families, and study investigators for their invaluable contribution.

\section{References}

1 Buchholz TA, Lehman CD, Harris JR, Pockaj BA, Khouri N, Hylton NF, Miller MJ, Whelan T, Pierce LJ, Esserman LJ, Newman LA, Smith BL, Bear HD and Mamounas EP: Statement of the science concerning locoregional treatments after preoperative chemotherapy for breast cancer: a National Cancer Institute conference. J Clin Oncol 26: 791-797, 2008. 
2 Kaufmann M, von Minckwitz G, Smith R, Valero V, Gianni L, Eiermann W, Howell A, Costa SD, Beuzeboc P, Untch M, Blohmer JU, Sinn HP, Sittek R, Souchon R, Tulusan AH, Volm $\mathrm{T}$ and Senn HJ: International Expert Panel on the Use of Primary (preoperative) Systemic Treatment of Operable Breast Cancer: review and recommendations. J Clin Oncol 21: 2600-2608, 2003.

3 Ring AE, Smith IE, Ashley S, Fulford LG and Lakhani SR: Oestrogen receptor status, pathological complete response and prognosis in patients receiving neoadjuvant chemotherapy for early breast cancer. Br J Cancer 91: 2012-2017, 2004.

4 Burcombe RJ, Makris A, Richman PI, Daley FM, Noble S, Pittam M, Wright D, Allen SA, Dove J and Wilson GD: Evaluation of ER, PgR, HER-2 and Ki-67 as predictors of response to neoadjuvant anthracycline chemotherapy for operable breast cancer. Br J Cancer 92: 147-155, 2005.

5 Colleoni M, Bagnardi V, Rotmensz N, Gelber RD, Viale G, Pruneri G, Veronesi P, Torrisi R, Cardillo A, Montagna E, Campagnoli E, Luini A, Intra M, Galimberti V, Scarano E, Peruzzotti $G$ and Goldhirsch A: Increasing steroid hormone receptors expression defines breast cancer subtypes non responsive to preoperative chemotherapy. Breast Cancer Res Treat 116: 359-369, 2009.

6 Rastogi P, Anderson SJ, Bear HD, Geyer CE, Kahlenberg MS, Robidoux A, Margolese RG, Hoehn JL, Vogel VG, Dakhil SR, Tamkus D, King KM, Pajon ER, Wright MJ, Robert J, Paik S, Mamounas EP and Wolmark N: Preoperative Chemotherapy: Updates of National Surgical Adjuvant Breast and Bowel Project Protocols B-18 and B-27. J Clin Oncol 26: 778-785, 2008.

7 Thomas E, Holmes FA, Smith TL, Buzdar AU, Frye DK, Fraschini G, Singletary SE, Theriault RL, McNeese MD, Ames F, Walters R and Hortobagyi GN: The use of alternate, noncross-resistant adjuvant chemotherapy on the basis of pathologic response to a neoadjuvant doxorubicin-based regimen in women with operable breast cancer: long-term results from a prospective randomized trial. J Clin Oncol 22: 2294-2302, 2004.

8 Kuerer HM, Newman LA, Smith TL, Ames FC, Hunt KK, Dhingra K, Theriault RL, Singh G, Binkley SM, Sneige N, Buchholz TA, Ross MI, McNeese MD, Buzdar AU, Hortobagyi GN and Singletary SE: Clinical course of breast cancer patients with complete pathologic primary tumor and axillary lymph node response to doxorubicin-based neoadjuvant chemotherapy. J Clin Oncol 17: 460-469, 1999.

9 Dent R, Trudeau M, Pritchard KI, Hanna WM, Kahn HK, Sawka CA, Lickley LA, Rawlinson E, Sun P and Narod SA: Triplenegative breast cancer: clinical features and patterns of recurrence. Clin Cancer Res 13: 4429-4434, 2007.

10 Nakayama $\mathrm{T}$ and Noguchi S: Therapeutic usefulness of postoperative adjuvant chemotherapy with tegafur-uracil (UFT) in patients with breast cancer: focus on the results of clinical studies in Japan. Oncologist 15: 26-36, 2010.

11 Noguchi S, Koyama H, Uchino J, Abe R, Miura S, Sugimachi $\mathrm{K}$, Akazawa $\mathrm{K}$ and Abe O: Postoperative adjuvant therapy with tamoxifen, tegafur plus uracil, or both in women with nodenegative breast cancer: a pooled analysis of six randomized controlled trials. J Clin Oncol 23: 2172-2184, 2005.

12 Watanabe T, Sano M, Takashima S, Kitaya T, Tokuda Y, Yoshimoto M, Kohno N, Nakagami K, Iwata H, Shimozuma K, Sonoo H, Tsuda H, Sakamoto G and Ohashi Y: Oral uracil and tegafur compared with classic cyclophosphamide, methotrexate, fluorouracil as postoperative chemotherapy in patients with nodenegative, high-risk breast cancer: National Surgical Adjuvant Study for Breast Cancer 01 Trial. J Clin Oncol 27: 1368-1374, 2009.

13 Park Y, Okamura K, Mitsuyama S, Saito T, Koh J, Kyono S, Higaki K, Ogita M, Asaga T, Inaji H, Komichi H, Kohno N, Yamazaki K, Tanaka F, Ito T, Nishikawa H, Osaki A, Koyama H and Suzuki T: Uracil-tegafur and tamoxifen $v s$. cyclophosphamide, methotrexate, fluorouracil, and tamoxifen in post-operative adjuvant therapy for stage I, II, or IIIA lymph node-positive breast cancer: a comparative study. Br J Cancer 101: 598-604, 2009.

14 Ohashi Y1, Watanabe T, Sano M, Koyama H, Inaji H and Suzuki T: Efficacy of oral tegafur-uracil (UFT) as adjuvant therapy as compared with classical cyclophosphamide, methotrexate, and 5-fluorouracil (CMF) in early breast cancer: a pooled analysis of two randomized controlled trials (N.SAS-BC 01 trial and CUBC trial). Breast Cancer Res Treat 119: 633-641, 2010.

15 Cancer Therapy Evaluation Program, Common Terminology Criteria for Adverse Events, Version 4.0, DCTD, NCI, NIH, DHHS December 23, 2009 (http://ctep.cancer.gov), Publish Date: June 14, 2010.

16 von Minckwitz G, Untch M, Blohmer JU, Costa SD, Eidtmann H, Fasching PA, Gerber B, Eiermann W, Hilfrich J, Huober J, Jackisch C, Kaufmann M, Konecny GE, Denkert C, Nekljudova $\mathrm{V}$, Mehta K and Loibl S: Definition and impact of pathologic complete response on prognosis after neoadjuvant chemotherapy in various intrinsic breast cancer subtypes. J Clin Oncol 30: 1796-1804, 2012.

17 Cortazar P, Zhang L, Untch M, Mehta K, Costantino JP, Wolmark N, Bonnefoi H, Cameron D, Gianni L, Valagussa P, Swain SM, Prowell T, Loibl S, Wickerham DL, Bogaerts J, Baselga J, Perou C, Blumenthal G, Blohmer J, Mamounas EP, Bergh J, Semiglazov V, Justice R, Eidtmann H, Paik S, Piccart M, Sridhara R, Fasching PA, Slaets L, Tang S, Gerber B, Geyer CE Jr., Pazdur R, Ditsch N, Rastogi P, Eiermann W and von Minckwitz G: Pathological complete response and long-term clinical benefit in breast cancer: the CTNeoBC pooled analysis. Lancet 384: 164-172, 2014.

18 Munoz R, Man S, Shaked Y, Lee CR, Wong J, Francia G and Kerbel RS: Highly efficacious nontoxic preclinical treatment for advanced metastatic breast cancer using combination oral UFTcyclophosphamide metronomic chemotherapy. Cancer Res 66: 3386-3391, 2006.

19 Toi M, Lee S-J, Lee ES, Ohtani S, Im Y-H, Im S-A, Park B-W, Kim S-B, Yanagita Y, Takao S, Ohno S, Aogi K, Iwata H, Kim A, Sasano H, Yokota I, Ohashi Y and Masuda N: A phase III trial of adjuvant capecitabine in breast cancer patients with HER2-negative pathologic residual invasive disease after neoadjuvant chemotherapy (CREATE-X, JBCRG-04). San Antonio Breast Cancer Symposium 2015; Abstract S1-07.

Received October 21, 2016

Revised November 7, 2016

Accepted November 8, 2016 